\title{
ESTRATÉGIAS DE EDUCAÇÃO FINANCEIRA PARA CRIANÇAS: CONSTRUINDO SITUAÇÕES DIDÁTICAS DE ECONOMIA EM SALA DE AULA
}

\author{
FINANCIAL EDUCATION STRATEGIES FOR CHILDREN: BUILDING \\ SITUATIONS OF ECONOMICS TEACHING IN THE CLASSROOM
}

\author{
HOFMANN, Ruth Margareth \\ ruthofmann@gmail.com \\ UFPR - Universidade Federal do Paraná \\ SOARES, Maria Tereza Carneiro \\ mariteufpr@gmail.com \\ UFPR - Universidade Federal do Paraná
}

\begin{abstract}
RESUMO Seguindo uma trajetória internacional de reconhecimento da importância formativa de competências econômicas e financeiras da população mundial, a institucionalização da educação financeira no Brasil, dada pelo Decreto $\mathrm{n}^{\circ} 7.397$ de 22 de dezembro de 2010, prevê um conjunto de medidas pedagógicas de letramento financeiro voltadas ao público adulto, jovem e infantil. Tendo sido abordada no ensino médio em diferentes Estados brasileiros em 2010, a perspectiva é de expansão da iniciativa para as crianças brasileiras. É nesse contexto que o presente trabalho tem por objetivo contribuir para o delineamento de metodologias do ensino de finanças para crianças mediante a construção de situações didáticas de economia em sala de aula. Parte-se do pressuposto de que a construção do conhecimento financeiro é imprescindível ao conhecimento econômico, sendo este entendido como o contexto maior capaz de conferir significado aos conceitos e às noções financeiras. As estratégias de abordagem de educação financeira propostas neste artigo foram inspiradas em estudos que analisam a construção infantil de noções econômicas. Para tanto, selecionaram-se trabalhos que empregam, em seu método de coleta de dados, técnicas que envolvem predominantemente atividades capazes de mobilizar conhecimentos econômicos. Argumentou-se que o método clínico crítico, preponderante dentre os trabalhos descritos anteriormente, possibilita a combinação de diferentes técnicas e que essa combinação pode resultar na criação de algumas situações com potencial didático para o ensino de conceitos econômicos.
\end{abstract}

PALAVRAS-CHAVE: Estratégias didáticas. Educação econômica. Educação financeira para crianças.

ABSTRACT Following an international trend to recognize the formative importance of economic and financial powers of the world population, the institutionalization of financial education in Brazil, given by Decree No. 7,397 of December 22, 2010, provides a set of pedagogical measures of financial literacy public-facing adult, youth 
and children. Having been raised in institutions of secondary education from different Brazilian states in 2010, on a pilot basis, is the prospect of expanding the initiative to educate financial financially Brazilian children. In this context, the present work aims to contribute to the design of methodologies of teaching finance to children by constructing teaching situations economics classroom. Breaks the assumption that the construction of financial knowledge is essential to economic knowledge, understood the larger context capable of giving meaning to concepts and financial concepts. Strategies for financial education approach proposed in this article were inspired by studies that examine child build economic notions. To this end, we selected works that employ in their method of data collection techniques involving predominantly economic activities capable of mobilizing knowledge. It was argued that the preponderant among the work described above, critical clinical method allows the combination of different techniques, and that this combination can result in creating some teaching situations with potential for teaching economic concepts.

KEYWORDS: Economic education. Financial education for children. Teaching strategies.

\section{INTRODUÇÃO}

Os objetos de conhecimento que figuram no currículo escolar recorrentemente disputam entre si o limitado tempo das atividades didáticas desenvolvidas no contexto institucional dos estabelecimentos de ensino, pleiteando o reconhecimento de sua importância formativa. Tais disputas alicerçam-se sobre discussões acerca da potencial relevância que cada um dos conteúdos pode ter em termos do desenvolvimento cognitivo e social dos estudantes. Indicam-se, nessas circunstâncias, argumentos de natureza técnica, psicológica e pragmática em prol de determinados conhecimentos, competências e habilidades.

Dentre o conjunto de competências que têm sido apontadas como fator de promoção da inclusão social, as relacionadas ao letramento financeiro ganharam destaque com o Decreto $n^{\circ}$. 7.397 de 22 de dezembro de 2010, que institui a Estratégia Nacional de Educação Financeira (ENEF), cuja finalidade é "[...] promover a educação financeira e previdenciária e contribuir para o fortalecimento da cidadania, a eficiência e solidez do sistema financeiro nacional e a tomada de decisões conscientes por parte dos consumidores." (BRASIL, 2010, s/p). A institucionalização da educação financeira no Brasil prevê um conjunto de medidas pedagógicas voltadas ao público adulto, jovem e infantil. A educação financeira foi abordada em estabelecimentos de ensino médio de diferentes Estados brasileiros 
em 2010, em caráter piloto. A perspectiva é de expansão da iniciativa para educar financeiramente as crianças brasileiras.

É nesse contexto que o presente trabalho tem por objetivo contribuir para o delineamento de metodologias do ensino de finanças para crianças mediante a construção de situações didáticas de economia em sala de aula. Parte-se do pressuposto de que à construção do conhecimento financeiro é imprescindível o conhecimento econômico, sendo este um contexto maior, capaz de conferir significado aos conceitos e às noções financeiras. As estratégias de abordagem de educação financeira propostas neste artigo foram inspiradas em estudos que analisam a construção infantil de noções econômicas. Para tanto, selecionaram-se trabalhos que empregam, em seu método de coleta de dados, técnicas que envolvem predominantemente atividades capazes de mobilizar conhecimentos econômicos.

O artigo está estruturado em três seções além desta introdução. Na seção 2, faz-se uma breve revisão da literatura acerca dos trabalhos, cujo objeto é a construção infantil de conceitos econômicos. Na seção 3, descrevem-se os métodos de coleta de dados empregados por tais trabalhos à luz da sua potencial contribuição para a construção de situações didáticas para o ensino de finanças para crianças. Na seção 4, apresentam-se algumas possibilidades de situação construídas a partir dos métodos descritos na seção 3. Por fim, apresentam-se alguns apontamentos decorrentes do desenvolvimento do trabalho.

\section{COMO AS CRIANÇAS CONSTROEM O CONHECIMENTO ECONÔMICO}

Os esforços científicos dedicados à compreensão do processo de construção de noções econômicas têm encontrado na Psicologia Econômica referenciais analíticos e metodológicos profícuos ao empreendimento. Parcela importante desses trabalhos fundamenta-se, em sua maioria, em perspectivas piagetianas para abordar o processo de socialização econômica e a construção de determinadas noções de caráter econômico ou socioeconômico, a exemplo dos trabalhos de Furth (1980), Jahoda (1964; 1979; 1983), Berti et al. (1986), Leiser e Zaltsman (1990), Delval e Kohen (2001), Leiser e Halachmi (2006) e Hofmann (2011). Em essência, têm-se 
indícios significativos de que a compreensão de noções econômicas é um processo de construção elaborado que passa de concepções simples à raciocínios abstratos com o incremento da idade dos sujeitos.

Leiser (1983) investigou as concepções econômicas infantis à luz da construção de um domínio cognitivo, numa perspectiva piagetiana. O estudo pautouse pela realização de entrevistas e aplicação de um questionário posteriormente replicado por outros autores. Os 89 sujeitos da amostra foram crianças e adolescentes israelenses de sete a dezessete anos. O questionário tinha por objeto a noção de preços, salários, greves, poupança e investimento, fábricas, bancos e impressão de papel moeda. Propunha-se às crianças, por exemplo, as seguintes questões: "Como os preços são determinados?" ou "O que são salários?", "O que é uma greve?" e "Quem imprime o dinheiro?". O autor conclui que, inicialmente, as crianças veem as transações econômicas na perspectiva da participação individual, sem denotar preocupação com o sistema de forças econômicas que resulta das transações individuais. $\mathrm{Na}$ medida em que as crianças crescem, desenvolvem sistemas parciais de compreensão que passam a entrar em conflito e elas passam a tentar suprimi-lo. O esforço de eliminação de contradições persiste até que a criança seja capaz de construir sistemas relativamente harmônicos de compreensão da realidade econômica. $O$ tipo de conhecimento subjacente às noções incipientes incorpora-se nos modelos mais elaborados e maduros de compreensão dos fenômenos econômicos.

$\mathrm{Na}$ análise dos processos de socialização econômica, Harrah e Friedman (1990), tomando por base o questionário de Leiser (1983), entrevistaram cerca de 90 crianças norte-americanas para apreender sua compreensão de determinadas noções e atitudes econômicas, incluindo os preços, o funcionamento de estabelecimentos comerciais, o fluxo monetário, os salários, poupança, investimento e impostos. Os autores observam que as crianças mais novas conhecem apenas fragmentos isolados de informação econômica, enquanto as crianças mais velhas são capazes de compor subsistemas de conhecimento econômico relativamente integrados, argumentando que o processo verificado mantém aderência com a teoria do desenvolvimento de Piaget. O papel da experiência infantil pareceu importante na 
construção de sua compreensão dos fenômenos econômicos, particularmente, o contato com situações de compra.

O princípio de progressão na construção do conhecimento econômico foi identificado também por Wosinski e Pietras (1990), cujos procedimentos metodológicos foram semelhantes aos de Harrah e Friedman (1990), sendo pautado também pelo questionário de Leiser (1983). A partir da análise das entrevistas realizadas com crianças polonesas de oito, onze e catorze anos, o trabalho aponta semelhanças em relação aos resultados de Leiser (1983), com a ressalva de que o impacto de condições econômicas externas pareciam exercer papel significativo nas elaborações infantis das concepções econômicas investigadas. As diferenças de resposta identificadas entre as crianças foram parcialmente atribuídas ao fato de que as mais jovens nasceram sob condições de crise econômica na Polônia, o que se refletiu, em certa medida, em um conhecimento econômico mais bem elaborado.

Leiser e Halachmi (2006) utilizaram pequenas estórias e ilustrações para analisar a compreensão infantil das forças de mercado, tendo observado que as crianças em idade pré-escolar tendem a compreender primeiro os efeitos da demanda, e somente depois disso, conseguem compreender os efeitos da oferta. No mesmo sentido dos trabalhos mencionados anteriormente, essa tendência é caracterizada pela transição de sistemas parciais isolados para uma integração crescente de compreensão de distintos sistemas, bem como pela antecedência do desenvolvimento da compreensão de correlações positivas entre causa e efeito. Os autores acreditam que $\mathrm{o}$ fato de as crianças compreenderem mais facilmente $\mathrm{O}$ papel da demanda se deve parcialmente à familiaridade que elas mantêm com a posição de consumidoras, o que tende a expressar a influência da experiência na construção das noções econômicas.

Hofmann (2011) investigou um conjunto de noções econômicas que incluiu mercado, sistemas metrológicos, propriedade e troca, dinheiro moedas e cédulas, trabalho, mercadoria e preços, tendo por objetivo central avaliar o processo de construção da noção de valor econômico. No artigo, fez-se uso de ilustrações de mercadorias e não-mercadorias, bem como de moedas e cédulas, para estimular as crianças a promover classificações e ordenações de categorias econômicas. A autora aponta indícios de que a construção de um invariante quantitativo capaz de 
inserir o preço num sistema metrológico específico (econômico) é um processo complexo, e que a noção de "valor de uso" desenvolve-se, aparentemente, antes da noção de "valor de troca", sendo aquela um provável fundamento desta. O trabalho sugere que, sendo condição para a coordenação dos sistemas metrológicos implicados nas trocas econômicas, possivelmente é também condição (pré-requisito) para o desenvolvimento da noção de valor de troca (eminentemente quantitativa). Além disso, o trabalho indica que, dentre as crianças da amostra, observa-se uma transição de um conceito subjetivo de valor para um conceito objetivo, no qual os elementos quantitativos assumem, gradativamente, maior importância.

Davies e Lundholm (2012) analisaram a compreensão que sujeitos de diferentes idades (de 11 a 23 anos) expressam acerca de fenômenos socioeconômicos no intuito de identificar, dentre outros fatores, as diferenças qualitativas evidentes no raciocínio dos alunos sobre os motivos pelos quais determinado bem ou serviço é ou deve ser disponibilizado gratuitamente. Os autores procuraram identificar uma possível relação, no raciocínio dos sujeitos, entre o provimento gratuito dos bens e a natureza destes. Dentre os resultados obtidos, o trabalho indica que o conceito de normalidade mantido implicitamente pelos sujeitos exerce importância significativa em seu pensamento, assim como as noções de equidade e necessidade. Os autores indicam a relevância desses fatores para a composição do currículo.

\section{TÉCNICAS DE COLETA DE INFORMAÇÕES SOBRE A CONSTRUÇÃO DE CONCEITOS ECONÔMICOS}

No esforço de compreensão do processo de elaboração de noções econômicas, alguns trabalhos acerca da psicogênese recorrem a questionários e entrevistas semiestruturadas que podem, ou não, vir acompanhadas de atividades auxiliares com material passível de manipulação pela criança. Esse material, que normalmente exerce um papel metodológico na coleta de informações, subsidia a interação do pesquisador com a criança. O método clínico crítico, preponderante dentre os trabalhos descritos anteriormente, possibilita a combinação de diferentes técnicas, algumas com potencial didático para o ensino de conceitos econômicos. 
O questionário de Leiser (1983), por exemplo, compõe-se de perguntas formuladas em linguagem relativamente simples para entrevistar crianças a respeito das noções de preço, salário, greves, poupança e investimento, fábricas e bancos, conforme indicado no

Quadro 1. As questões abrangem a origem, a função, relações de causalidade e funcionamento dessas categorias econômicas.

Quadro 1 - questionário elaborado para coletar dados sobre a construção infantil de noções econômicas

\begin{tabular}{|c|c|}
\hline Noção investigada & Questões propostas \\
\hline Preço & $\begin{array}{l}\text { 1. Você vai com frequência ao supermercado sozinho? } \\
\text { 2. Como os preços de lá são determinados? } \\
\text { 3. O lojista pode pedir quanto ele quiser? (se não: Quem decide?) (Se sim: por } \\
\text { que ele não pede mais?) } \\
\text { 4. O que ele faz com o dinheiro que recebe? O que mais? } \\
\text { 5. Você sabe o que é inflação? (se sim: Por favor, fale mais a respeito). } \\
\text { 6. Isso é bom ou ruim? Por quê? } \\
\text { 7. Você diria que os preços em Israel [país de origem das crianças } \\
\text { entrevistadas] tendem a aumentar ou diminuir? } \\
\text { 8. Por quê? Você pode pensar nas razões? } \\
\text { 9. Como os preços são determinados? (se alguém decide: Como ele sabe?) } \\
\text { Suponha que se anunciasse na rádio que os preços dos sapatos fossem cair. } \\
\text { 10. O que a mamãe acharia disso? } \\
\text { 11. Como o lojista se sentiria a respeito? } \\
\text { 12. Como o chefe da fábrica reagiria? } \\
\text { 13... e o governo? } \\
\text { 14. O que aconteceria se os preços continuassem a subir e subir? O que } \\
\text { aconteceria então? }\end{array}$ \\
\hline Salário & $\begin{array}{l}\text { 15. O que são salários? } \\
\text { 16. Quem os recebe? } \\
\text { 17. Quem os paga? Alguém mais? } \\
\text { 18. De onde vem o dinheiro? De onde mais? } \\
\text { 19. Todo mundo ganha o mesmo valor? } \\
\text { 20. Como esse valor é determinado? }\end{array}$ \\
\hline
\end{tabular}




\begin{tabular}{|c|c|}
\hline & $\begin{array}{l}\text { 21. Quem decide? } \\
\text { 22. O que as pessoas podem fazer se acharem que não ganham o bastante? O } \\
\text { que mais? }\end{array}$ \\
\hline Greve & $\begin{array}{l}\text { 23. O que é uma greve? } \\
\text { 24. Quem decide que haverá uma greve? } \\
\text { 25. Por que algumas vezes as pessoas fazem greve? } \\
\text { 25.a. (se for para pagar mais: Quem deveria pagar mais?) } \\
\text { 26. Como a greve ajuda (a atingir o objetivo)? }\end{array}$ \\
\hline $\begin{array}{l}\text { Poupança e } \\
\text { investimento }\end{array}$ & $\begin{array}{l}\text { 27. O que uma pessoa que tem mais dinheiro do que precisa gastar pode } \\
\text { fazer? O que mais? } \\
\text { 28. Como ela pode aumentar a quantidade até que tenha o que precisa? (Se o } \\
\text { banco der mais: Por que ela precisa do banco para isso?) }\end{array}$ \\
\hline Fábricas e bancos & $\begin{array}{l}\text { 29. O que é uma fábrica? } \\
\text { 30. Como as fábricas começaram? } \\
\text { 31. Por que elas começaram? } \\
\text { 32. É possível começar uma fábrica hoje? } \\
\text { 33. Qualquer um pode? } \\
\text { 34. Por que alguém faria isso? } \\
\text { 35. Como os bancos começaram? } \\
\text { 36. Quem decidiu começá-los? } \\
\text { 37. Isso ainda é possível hoje? }\end{array}$ \\
\hline A casa da moeda & $\begin{array}{l}\text { 38. Quem imprime o dinheiro? } \\
\text { 39. Quem decide quanto imprimir? } \\
\text { 40. Como ele[s] sabe[m]? } \\
\text { 41. O que aconteceria se eles imprimissem muito dinheiro e distribuíssem para } \\
\text { as pessoas? }\end{array}$ \\
\hline
\end{tabular}

Fonte: Leiser (1983), tradução livre.

Leiser e Halachmi (2006), por outro lado, empregam breves estórias com ilustrações no intuito de apresentar às crianças de sua amostra, situações-problema capazes de explorar seu conhecimento sobre as forças de mercado (oferta e demanda). Na primeira narrativa, intitulada Car wash (lava-car), a pequena Dorit, 
protagonista, é apresentada por meio de uma imagem (Figura 1), servindo para que o pesquisador relate à criança entrevistada que na vizinhança da personagem todos lavam o carro uma vez por semana. Na narrativa consta que em suas férias de verão, a protagonista decide abrir um negócio: um lava-car. Para apoiá-la, sua mãe Ihe dá o material necessário: um balde, alguns trapos e muito sabão. Com o material em mãos, a pequena Dorit parte para o estacionamento onde se ofereceu para lavar os carros dos motoristas que lá estavam em troca de dez moedas para cada um dos carros lavados.

Figura 1 - A protagonista da estória criada para apreender a compreensão infantil das forças de mercado (Dorit) e seus concorrentes
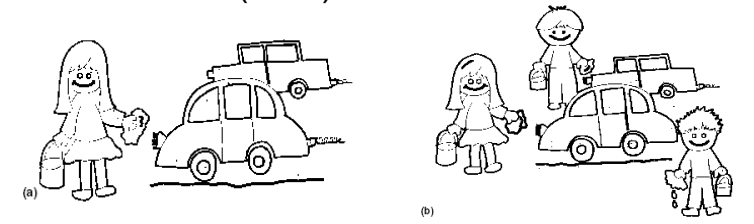

Fonte: Leiser e Halachmi (2006, p. 16)

Com o movimento no lava-car de Dorit, outras crianças da vizinhança perceberam, na semana seguinte, que a menina estava ganhando muito dinheiro, 0 que estimulou cada uma delas a abrir seu próprio lava-car. Nesse ponto, todas as crianças já estavam no estacionamento, cada uma com seus materiais (os trapinhos, o balde d'água e o sabão). A narrativa encerra-se com o episódio segundo, o qual as crianças gritavam para qualquer carro que passar: "Venha e deixe-me lavar seu carro!". Com isso, questiona-se a criança quanto às suas expectativas em relação ao preço da lavagem: se vai aumentar, diminuir ou se permanecerá o mesmo que antes.

Na segunda estória proposta por Leiser e Halachmi (2006), a classe do protagonista (Ido) coleciona e troca figuras de jogadores de futebol americano entre si. A figura de um jogador (Revivo) é a preferida da turma. No intervalo da aula, Ido trocaria figurinhas com seu colega Shmulik: se Ido der a Shmulik uma figurinha de Revivo terá, em troca, três figuras de outros jogadores comuns. Várias outras crianças, que queriam a figurinha de Revivo, cercaram Ido para trocar suas figurinhas pela de Revivo. Finda a narrativa, pergunta-se à criança se Ido receberia mais, menos ou a mesma quantidade de figurinhas de jogadores comuns em troca 
da preferida pelas crianças. Pergunta-se, ainda à criança entrevistada, como Ido deveria decidir com quem trocar, bem como se o protagonista aceitaria cinco figurinhas em troca da de Revivo e qual a disposição das demais crianças diante da oferta de cinco figurinhas por uma.

A terceira história utilizada por Leiser e Halachmi (2006) tem como protagonista Naama, uma excelente cozinheira, cuja especialidade são docinhos de chocolate. Yoav, outro personagem, aprecia os docinhos de chocolate e os compra regularmente de Naama. Aos poucos, as crianças da vizinhança ouvem falar dos doces de Naama e também passam a comprá-los. Pergunta-se às crianças se, com a intenção de compra das demais crianças da vizinhança, o preço permanecerá o mesmo, aumentará ou cairá. O entrevistador questiona a criança quanto a o quê aconteceria se restasse apenas um doce e todas as crianças quisessem comprá-lo. Além disso, apresentam-se à criança possibilidades de preço e de propostas para que exponha o resultado que imagina.

Hofmann (2011) utiliza figuras de mercadorias e de não-mercadorias (Figura 2), além de figuras de moedas e cédulas de reais para analisar a psicogênese do valor econômico em crianças. Inicialmente, o entrevistador pede à criança para que separe as imagens de mercadorias e de não-mercadorias (o que há no mercado para vender e o que não há), itens que são ou não economicamente precificáveis e comercialmente intercambiáveis. O termo "mercado" é considerado, para efeito da entrevista, no sentido de instituição e equivalente de qualquer estabelecimento comercial (loja, venda, feira etc.).

Figura 2 - Ilustrações de mercadorias e não-mercadorias utilizadas para abordar

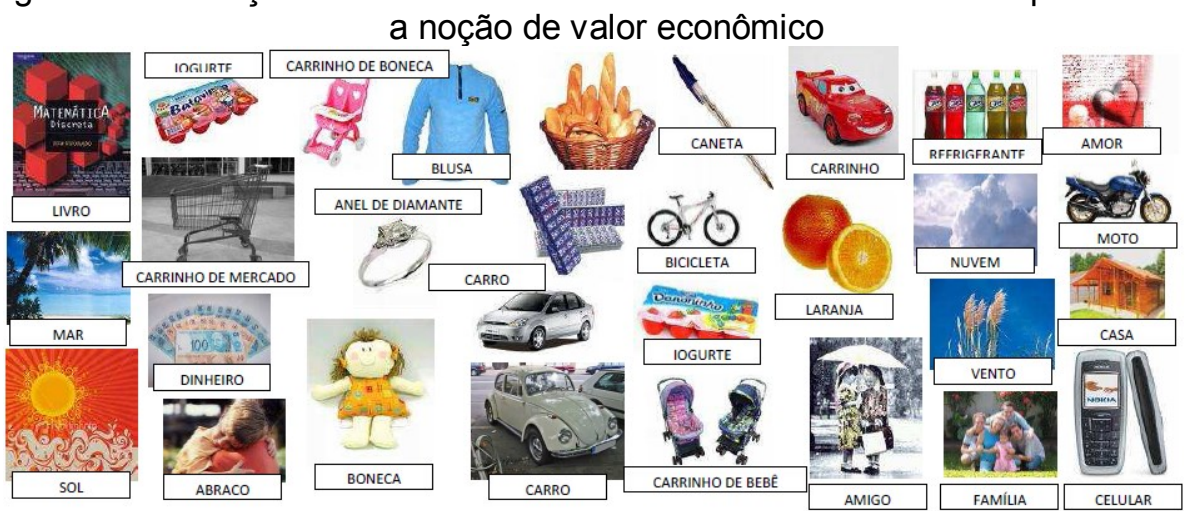

Fonte: Hofmann (2011). 
O objetivo da tarefa proposta por Hofmann (2011) é análogo ao das questões que Davies e Lundholm (2012) propõem para a identificação de bens gratuitos: "O que deveria ser gratuito para todo mundo? Por quais itens as pessoas deveriam pagar?". Davies e Lundholm (2012) apresentam uma lista para que os estudantes entrevistados classifiquem. A lista inclui: sentar em uma praia; hambúrguer; frutas; estudar em uma universidade; água; assistir a um filme no cinema; e dirigir carros na estrada.

$\mathrm{Na}$ abordagem de Hofmann (2011), pede-se à criança que explique a separação entre as ilustrações de mercadorias e não-mercadorias. Em seguida, o entrevistador deve solicitar-lhe que selecione apenas as mercadorias e que as enfileire do item mais barato para o item mais caro, em ordem crescente, tarefa cujo propósito é identificar o nível de compreensão do aspecto quantitativo subjacente ao preço, cabendo observar o emprego de critérios figurativos e não figurativos (por exemplo: mercadorias maiores são mais caras e menores mais baratas etc.). Complementarmente, apresentam-se figuras de cédulas e moedas à criança, solicitando que as atribua valor e as ordene da que tem maior valor para a que tem menor. Em seguida, pede-se que, utilizando cédulas e moedas, ela componha alguns valores referentes ao preço indicado para alguma mercadoria ou que componha o valor de outras cédulas ou moedas. Nesse contexto, a criança é questionada sobre alguns elementos do sistema de mensuração específico ao valor econômico, sobretudo, a noção de preço.

\section{CRIANDO SITUAÇÕES DE EDUCAÇÃO ECONÔMICA PARA CRIANÇAS NA ESCOLA}

As situações construídas para a coleta de dados acerca da psicogênese de conceitos econômicos, soam inspiradoras para a construção de situações com potencial didático em sala de aula. Quando o professor assume a posição, até então ocupada pelo entrevistador, pode intervir, pedagogicamente, estimulando a construção cognitiva de conceitos essencialmente socioeconômicos. As questões propostas às crianças por ocasião das entrevistas podem ser revertidas em roteiros temáticos, operando como tópicos de discussão conduzida pelo professor, a quem compete a introdução dos conceitos. Para tanto, faz-se necessária a criação de um 
contexto ou situação para abordá-los. O Quadro 2 apresenta exemplos de situações com potencial didático que podem ser inseridas no ambiente escolar para o ensino de noções econômicas.

Quadro 2 - exemplos de situações com potencial didático para a construção de noções econômicas em sala de aula

\begin{tabular}{|c|c|c|}
\hline $\begin{array}{c}\text { Noção } \\
\text { abordada }\end{array}$ & Procedimentos & Questões orientadoras \\
\hline Preço & $\begin{array}{l}\text { 1. Selecionar encartes de lojas ou } \\
\text { supermercados, anúncios com ilustrações } \\
\text { de produtos próximos à realidade das } \\
\text { crianças e com registros de preços. } \\
\text { 2. Identificar os sistemas metrológicos } \\
\text { constantes no material até destacar os } \\
\text { registros de preços e sua notação } \\
\text { específica. } \\
\text { 3. Proceder às discussões considerando as } \\
\text { questões propostas, provendo às crianças } \\
\text { das respectivas explicações. }\end{array}$ & $\begin{array}{l}\text { 1. O que há no supermercado? } \\
\text { 2. Como os preços de lá são } \\
\text { determinados? } \\
\text { 3. O lojista pode pedir quanto ele } \\
\text { quiser? (se não: Quem decide?) } \\
\text { (Se sim: por que ele não pede } \\
\text { mais?) } \\
\text { 4. O que ele faz com o dinheiro } \\
\text { que recebe? O que mais? } \\
\text { 5. Você sabe o que é inflação? (se } \\
\text { sim: Por favor, fale mais a } \\
\text { respeito). } \\
\text { 6. Isso é bom ou ruim? Por quê? } \\
\text { 7. Você diria que os preços } \\
\text { tendem a aumentar ou diminuir? } \\
\text { 8. Por quê? Você pode pensar nas } \\
\text { razões? } \\
\text { 9. Como os preços são } \\
\text { determinados? (se alguém decide: } \\
\text { Como ele sabe?) Suponha que se } \\
\text { anunciasse na rádio que os } \\
\text { preços dos sapatos fossem cair. } \\
\text { 10. O que a mamãe acharia } \\
\text { disso? } \\
\text { 11. Como o lojista se sentiria a } \\
\text { respeito? } \\
\text { 12. Como o chefe da fábrica } \\
\text { reagiria? } \\
\text { 13... e o governo? } \\
\text { 14. O que aconteceria se os }\end{array}$ \\
\hline
\end{tabular}




\begin{tabular}{|c|c|c|}
\hline & & $\begin{array}{l}\text { preços continuassem a subir e } \\
\text { subir? O que aconteceria então? }\end{array}$ \\
\hline Salário & $\begin{array}{l}\text { 1. Apresentar ilustrações de personagens } \\
\text { representativos de diferentes tipos de } \\
\text { trabalho remunerado e não remunerado e, } \\
\text { em especial, de diferentes profissões. } \\
\text { 2. Explorar as diferenças de atribuição e } \\
\text { função. } \\
\text { 3. Introduzir, a partir das ilustrações, a noção } \\
\text { da remuneração pelo trabalho. } \\
\text { 4. Proceder às discussões considerando as } \\
\text { questões propostas, provendo às crianças } \\
\text { das respectivas explicações. }\end{array}$ & $\begin{array}{l}\text { 1. O que são salários? } \\
\text { 2. Quem os recebe? } \\
\text { 3. Quem os paga? Alguém mais? } \\
\text { 4. De onde vem o dinheiro? De } \\
\text { onde mais? } \\
\text { 5. Todo mundo ganha o mesmo } \\
\text { valor? } \\
\text { 6. Como esse valor é } \\
\text { determinado? } \\
\text { 7. Quem decide? } \\
\text { 8. O que as pessoas podem fazer } \\
\text { se acharem que não ganham o } \\
\text { bastante? O que mais? }\end{array}$ \\
\hline Greve & $\begin{array}{l}\text { 1. Apresentar notícias recentes sobre } \\
\text { movimentos grevistas próximos à realidade } \\
\text { das crianças, a exemplo dos sistemas de } \\
\text { transporte públicos. } \\
\text { 2. Proceder às discussões considerando as } \\
\text { questões propostas, provendo às crianças } \\
\text { das respectivas explicações. }\end{array}$ & $\begin{array}{l}\text { 1. O que é uma greve? } \\
\text { 2. Quem decide que haverá uma } \\
\text { greve? } \\
\text { 3. Por que algumas vezes as } \\
\text { pessoas fazem greve? } \\
\text { 3.a. (se for para pagar mais: Quem } \\
\text { deveria pagar mais?) } \\
\text { 4. Como a greve ajuda (a atingir o } \\
\text { objetivo)? }\end{array}$ \\
\hline $\begin{array}{l}\text { Poupança e } \\
\text { investimento }\end{array}$ & $\begin{array}{l}\text { 1. Apresentar ilustrações de caráter } \\
\text { metafórico, utilizando grãos (sementes) para } \\
\text { introduzir o conceito de investimento (cada } \\
\text { grão produz diversos outros) e de poupança } \\
\text { (para produzir é necessário abrir mão do } \\
\text { consumo de parte da safra). } \\
\text { 2. Estabelecer a comparação com o dinheiro e } \\
\text { o sistema bancário. } \\
\text { 3. Proceder às discussões considerando as } \\
\text { questões propostas, provendo às crianças } \\
\text { das respectivas explicações. }\end{array}$ & $\begin{array}{l}\text { 1. O que uma pessoa que tem } \\
\text { mais dinheiro do que precisa } \\
\text { gastar pode fazer? O que mais? } \\
\text { 2. Como ela pode aumentar a } \\
\text { quantidade até que tenha o que } \\
\text { precisa? (Se o banco der mais: Por } \\
\text { que ela precisa do banco para } \\
\text { isso?) }\end{array}$ \\
\hline $\begin{array}{l}\text { Fábricas } \mathrm{e} \\
\text { bancos }\end{array}$ & $\begin{array}{l}\text { 1. Apresentar ilustrações de diversos produtos } \\
\text { às crianças, com a preocupação de } \\
\text { apresentar bens intermediários, insumos e }\end{array}$ & $\begin{array}{l}\text { 1. O que é uma fábrica? } \\
\text { 2. Como as fábricas começaram? } \\
\text { 3. Por que elas começaram? }\end{array}$ \\
\hline
\end{tabular}




\begin{tabular}{|c|c|c|}
\hline & $\begin{array}{l}\text { bens finais. } \\
\text { 2. Introduzir a noção de produção e de } \\
\text { circulação, bem como os atores econômicos } \\
\text { que tomam parte no processo. } \\
\text { 3. Da noção de circulação, ressaltar a } \\
\text { importância do dinheiro e introduzir o papel } \\
\text { do sistema bancário. } \\
\text { 4. Proceder às discussões considerando as } \\
\text { questões propostas, provendo às crianças } \\
\text { das respectivas explicações. }\end{array}$ & $\begin{array}{l}\text { 4. É possível começar uma fábrica } \\
\text { hoje? } \\
\text { 5. Qualquer um pode? } \\
\text { 6. Por que alguém faria isso? } \\
\text { 7. Como os bancos começaram? } \\
\text { 8. Quem decidiu começá-los? } \\
\text { 9. Isso ainda é possível hoje? }\end{array}$ \\
\hline $\begin{array}{l}\text { A casa da } \\
\text { moeda }\end{array}$ & $\begin{array}{l}\text { 1. Introduzir dentre as mercadorias do contexto } \\
\text { anterior (noção de fábrica e de banco), } \\
\text { ilustrações das diferentes representações } \\
\text { dos meios de pagamento (moedas, cédulas, } \\
\text { cheques, cartões etc.). } \\
\text { 2. Apresentar o banco como estabelecimento } \\
\text { comercial que transaciona dinheiro (crédito). } \\
\text { 3. Introduzir os papeis institucionais } \\
\text { subjacentes ao caráter simbólico do } \\
\text { dinheiro. } \\
\text { 4. Proceder às discussões considerando as } \\
\text { questões propostas, provendo às crianças } \\
\text { das respectivas explicações. }\end{array}$ & $\begin{array}{l}\text { 1. Quem imprime o dinheiro? } \\
\text { 2. Quem decide quanto imprimir? } \\
\text { 3. Como ele[s] sabe[m]? } \\
\text { 4. O que aconteceria se eles } \\
\text { imprimissem muito dinheiro e } \\
\text { distribuíssem para as pessoas? }\end{array}$ \\
\hline
\end{tabular}

Fonte: Elaborado a partir do questionário de Leiser (1983).

Nesse mesmo sentido, as estórias de Leiser e Halachmi (2006) são potencialmente profícuas, na medida em que as situações-problema apresentadas podem ser discutidas e criam condições para a introdução de noções de oferta e demanda como conceitos econômicos importantes no cotidiano das próprias crianças. Fazendo-se uso da primeira narrativa dos autores, pode-se explicar às crianças o papel que excessos de oferta ou excessos de demanda tendem a exercer sobre os preços dos mais variados bens e serviços. A análise da narrativa pode começar com a própria identificação de uma oportunidade de negócios. Quando a pequena Dorit percebe um padrão em sua vizinhança - todos os vizinhos lavam seus carros periodicamente -, sente-se estimulada a prestar seus serviços e obter ganhos financeiros a partir disso. Aqui, abre-se a possibilidade de explorar o 
conceito de insumo, elencando-se o material necessário para a prestação dos serviços. A discussão pode pautar-se inclusive pelos custos de cada um dos insumos necessários, o que requer a apresentação de uma hipótese às crianças, supondo que Dorit tivesse de adquirir um balde, alguns trapos e muito sabão. Essa temática pode incluir estimativas de custo que servirão, posteriormente, para a formação de uma estimativa de preço (na estória a protagonista lava cada veículo em troca de 10 moedas).

llustrações auxiliares de cada um dos insumos necessários podem dar suporte à formação de um orçamento. Seriam igualmente úteis os encartes de supermercado que possibilitassem o exercício de comparação de preços, estimulando as crianças a desenvolverem inclusive noções quantitativas. Diz-se aos estudantes que a mãe da protagonista lhe deu determinada quantia monetária (por exemplo, $R \$ 10,00)$ e que a menina deve comprar todo o material sozinha. Com essa restrição orçamentária, as crianças devem ajudá-la a selecionar os produtos cujos preços não superem o auxílio monetário cedido pela mãe. Tendo selecionado os produtos com preços adequados à restrição, pode-se estimular os pequenos a definirem o preço a ser cobrado pelo serviço prestado.

Seguindo a narrativa, cabe a explicação dos efeitos da concorrência decorrentes da abertura dos novos negócios - as outras crianças que passaram a imitar o negócio de Dorit. Cabe espaço para a introdução do conceito de monopólio, condição inicial da estória, quando da decisão da protagonista de abrir seu próprio lava-car. Pode-se conjecturar acerca do custo dos materiais adquiridos pelos concorrentes e do impacto dessas diferenças sobre os preços que podem cobrar e os lucros que podem obter com a prestação do serviço. Além disso, pode-se discutir sobre as disposições individuais de se aceitar preços maiores ou menores, o que teria efeito sobre o "mercado" iniciado por Dorit.

A segunda estória proposta por Leiser e Halachmi (2006), sobre troca de figurinhas entre crianças, pode servir para discussões acerca do papel das preferências na definição do valor das mercadorias. Os conceitos de raridade e escassez podem ser introduzidos como fatores importantes na construção dos critérios de equivalência desenvolvidos pelas crianças para realização da troca. Convém criar conjecturas para incentivar as crianças a pensarem a respeito de tais 
fatores. Por exemplo, deve-se mencionar que se todas as crianças já possuíssem a figura de Revivo, dificilmente o protagonista seria tão assediado para trocas. Podese estabelecer a conexão entre escambo e trocas mediadas por dinheiro, criando-se um quadro para discussões sobre o valor monetário de diversas mercadorias.

A terceira estória, utilizada por Leiser e Halachmi (2006), pode ser abordada de forma análoga à primeira narrativa, cujo foco estava no excesso de oferta e no resultado disso sobre os preços da lavagem de carros. Os ingredientes necessários para os docinhos podem ser elencados, seus preços podem ser comparados para elaboração de um orçamento que serviria para a estimativa do preço por unidade de doce vendido. A narrativa dá margem à discussão da disposição individual que cada um dos apreciadores de chocolate teria para adquirir os doces e, em caso extremo, o último doce restante. Também pode-se abordar o fato de que cada um dos compradores defronta-se com restrições monetárias e que isso afeta o preço que estão dispostos a pagar pelos docinhos.

As técnicas empregadas por Hofmann (2011) podem igualmente proporcionar situações potencialmente didáticas de ensino de noções econômicas para crianças. As figuras de mercadorias e de não-mercadorias podem fornecer as bases para um exercício de classificação fundamentado em critérios econômicos. As classes de mercadorias podem ser decompostas em bens duráveis, não duráveis e intermediários por exemplo. A busca de um aspecto comum a ilustrações qualitativamente diferentes, a partir de uma perspectiva econômica, pode ser o fundamento de um exercício de ordenação com base em um critério quantitativo. Pode-se solicitar às crianças que indiquem suas estimativas de preço para cada uma das ilustrações consideradas mercadorias. Solicita-se então às crianças que ordenem, de forma crescente ou decrescente, as ilustrações com as respectivas estimativas de preço. As estimativas podem ser discutidas em termos das razões pelas quais uma mercadoria qualquer é mais cara ou mais barata do que outra, o que dá margem à introdução de noções como custo, utilidade, trabalho e preferências.

Convém ainda explorar a origem das mercadorias em termos do processo de produção, do papel das empresas e dos estabelecimentos comerciais. Para tanto, basta que uma dentre as ilustrações das mercadorias seja selecionada para instigar 
os alunos a pensarem a respeito da necessidade de sua produção, dos insumos necessários para sua transformação e dos custos desses insumos que podem ser posteriormente considerados para a composição de seu preço. A função dos estabelecimentos comerciais (lojas, supermercados, shoppings etc.) pode ser considerada nesse mesmo contexto. O conceito de preço pode ser vinculado as unidades de medida com as quais os consumidores se deparam em estabelecimentos comerciais. Além disso, os registros numéricos empregados pelas crianças para apresentar suas estimativas podem ser tomadas no contexto dos sistemas de medida com os quais se defrontam em situações econômicas típicas.

Complementarmente, análoga à ordenação das mercadorias, pode-se proceder à ordenação de moedas e cédulas, propondo-se alguns exercícios de composição e decomposição de unidades monetárias numa perspectiva concomitantemente aritmética e econômica. A função do dinheiro pode ser explicada à luz da noção de equivalência, propondo-se às crianças que estabeleçam a composição de quantias monetárias correspondentes aos preços de determinadas mercadorias, a partir de diferentes combinações de ilustrações de moedas e cédulas. Assim, como no caso das mercadorias, pode-se estimular as crianças a pensarem sobre a origem do dinheiro, sobre o papel das instituições bancárias e sobre as diferentes modalidades de representação desse instrumento de troca, que opera como meio de pagamento. Além disso, as funções do dinheiro podem ser explicadas por ocasião dos exercícios de ordenação, composição e equivalência entre cédulas e moedas. Dessa forma, as noções econômicas podem ser introduzidas na dinâmica escolar de forma integrada com conceitos matemáticos já consolidados no currículo escolar.

\section{CONSIDERAÇÕES FINAIS}

No contexto da institucionalização da educação financeira no Brasil, o presente trabalho teve por objetivo contribuir para o delineamento de metodologias do ensino de finanças para crianças mediante a construção de situações didáticas de economia em sala de aula. O pressuposto assumido foi o de que à construção do conhecimento financeiro é imprescindível o conhecimento econômico, sendo este 
considerado o contexto maior potencialmente capaz de conferir significado aos conceitos e às noções financeiras. Por essa razão, as estratégias de abordagem de educação financeira propostas neste artigo foram inspiradas em estudos que analisam a construção infantil de noções econômicas.

Argumentou-se que o método clínico crítico, preponderante dentre os trabalhos descritos anteriormente, possibilita a combinação de diferentes técnicas, e que essa combinação pode resultar na criação de algumas situações com potencial didático para o ensino de conceitos econômicos. As técnicas abordadas para efeito da criação de situações foram, em essência, o questionário elaborado por Leiser (1983), as estórias elaboradas por Leiser e Halachmi (2006) e o recurso à ilustrações de moedas, cédulas, mercadorias e não-mercadorias tal como utilizadas por Hofmann (2011).

Fazendo uso de técnicas de coleta de dados para fins didáticos, pode-se empregar, em sala, o material que normalmente exerce um papel metodológico na coleta de informações de trabalhos sobre a psicogênese de conceitos econômicos. Nesse sentido, têm-se elementos indicativos de que, quando o professor assume a posição até então ocupada pelo entrevistador, pode intervir pedagogicamente de forma a estimular a construção cognitiva de conceitos financeiros e econômicos. Por um lado, as questões propostas às crianças por ocasião das entrevistas, podem ser transformadas em roteiros temáticos que funcionam como tópicos de discussão conduzida pelo professor, a quem cabe a introdução dos conceitos econômicos e financeiros. Por outro lado, as estórias econômicas e as técnicas de classificação e ordenação de objetos econômicos podem operar como contexto ou ponto de partida para o ensino de noções financeiras e econômicas para crianças.

Trata-se, indubitavelmente, de um esforço módico e primário diante do desafio em que consiste o ensino de economia e finanças para crianças. Não obstante, pretende-se, com isso, abrir um espaço para a discussão sobre as estratégias didáticas e pedagógicas mais adequadas para abordar uma temática de relevância formativa há pouco institucionalmente reconhecida, qual seja, a educação financeira.

\section{RUTH HOFMANN}


Doutora em Educação pela Universidade Federal do Paraná - UFPR. Professora assistente do curso de graduação em Engenharia de Produção da UFPR.

\section{MARIA TEREZA CARNEIRO SOARES}

Doutora em Educação pela Universidade de São Paulo - USP. Professora adjunto da Universidade Federal do Paraná - UFPR.

\section{REFERÊNCIAS}

BERTI, A. E.; BOMBI, A. S.; DE BENI, R. The development of economic notions: single sequence or separate acquisitions? Journal of Economic Psychology, v. 7, p. 415-424, 1986.

BRASIL. Decreto $n^{\circ} 7.397$ - 22dez. 2010. Institui a Estratégia Nacional de Educação Financeira - ENEF, dispõe sobre a sua gestão e dá outras providências. Disponível em: <http://www.planalto.gov.br/ccivil_03/_Ato2007-2010/2010/Decreto/D7397.htm> Acesso em: 23 fev. 2012.

DAVIES, P.; LUNDHOLM, C. Students' understanding of socio-economic phenomena: conceptions about the free provision of goods and services. Journal of Economic Psychology, v. 33, p. 79-89, 2012.

DELVAL, J.; KOHEN, R. Paper presented at the 31st Annual Meeting of The Jean Piaget Society. The Genetic Epistemologist, v. 29, n. 2. Berkeley, CA: JPS, 2001 (mimeo)

FURTH, H. G. The world of grown-ups: children's conceptions of society. New York: Elsevier North Holland, 1980.

HARRAH, J.; FRIEDMAN, M. Economic socialization in children in a Midwestern american community. Journal of Economic Psychology, v. 11, p. 495-513, 1990.

HOFMANN, R. M. The psychogenesis of economic value. Conference Papers of IIPPE - International Initiative for Promoting Political Economy. Disponível em: <http://www.iippe.org/wiki/images/d/db/CONF_2011_Ruth_Hofmann_Psychogenesis. pdf> Acesso em: 27 fev. 2012.

JAHODA, G. Children's concepts of nationality: a critical study of Piaget's stages. Child Development, n. 35, p. 1081-1092, 1964.

. The construction of economic reality by some Glaswegian children. European Journal of Social Psychology, n. 9, p. 115-127, 1979.

. European 'lag' in the development of an economic concept: a study in

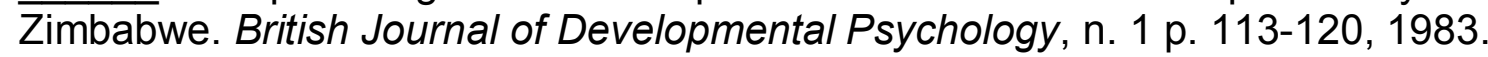


LEISER, D. Children's conceptions of economics: the constitution of a cognitive domain. Journal of Economic Psychology, v. 4, p. 297-317, 1983.

LEISER, D.; HALACHMI, R. B. Children's understanding of market forces. Journal of Economic Psychology, v.27, p. 6-19, 2006.

LEISER D.; ZALTSMAN, J. Economic socialization in the kibbutz and the town in Israel. Journal of Economic Psychology, v. 11, p. 557-565, 1990.

WOSINSKI, M.; PIETRAS, M. Economic socialization of polish children in different macro-economic conditions. Journal of Economic Psychology, v. 11, p. 515-528, 1990. 